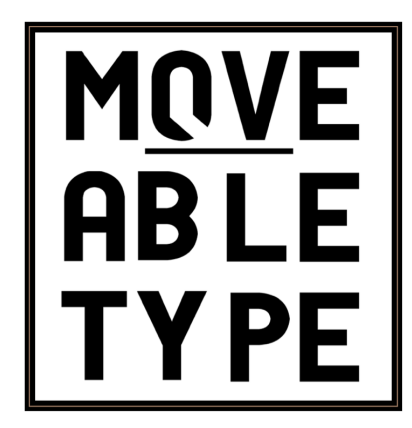

'Time on our hands in Ali Smith's Summer'

Author: Flora Sagers

Source: Moveable Type, Vol.13, 'Ambience' (2021)

DOI: $10.14324 / 111.1755-4527.121$

MoveableType is a Graduate, Peer-Reviewed Journal based in the Department of English at UCL.

(C) 2021 Flora Sagers. This is an Open Access article distributed under the terms of the Creative Commons Attribution License (CC-BY) 4.ohttps://creativecommons.org/licenses/by/4.0/, which permits unrestricted use, distribution, and reproduction in any medium, provided the original author and source are credited. 


\title{
Time on our hands in Ali Smith's Summer
}

\section{Flora Sagers}

\author{
Summer. By Ali Smith. 2020. 379p. £16.99. Hamish Hamilton.
}

ISBN 978-0-241-20706-2.

During the pandemic, we have all renegotiated the time on our hands, regardless of circumstance. Many found themselves struggling to balance new schedules as schools shut; others were thrown into the white space of empty diaries, devoid of social and work commitments. This shift in our relationship to time is the central concern of Ali Smith's pandemic novel, Summer, the final instalment of her seasonal quartet. Smith's series has always been preoccupied with time; it utilises a radically shortened publication process, and this allows the quartet to remain open to the present, attaining a unique sense of urgency. By condensing the production time of this quartet, Smith has created truly ambient literature; literature that holds the reader in their own socio-historical moment by responding to and reflecting on the most significant events of British contemporary history.

Smith's quartet is framed by these events - Brexit in Autumn (2016), and the Covid-19 pandemic in Summer - that the first and last novels in this series can be defined by the events they grapple with, as much as with the seasons they are ostensibly preoccupied by, is a true testament to the ambience of this series, and the multifaceted nature of its preoccupation with time. Time in Smith's series is both: eternal - in the cyclical nature of the seasons, and political - capturing and preserving the concerns of the contemporary moment. In Summer, Smith crystalises her engagement with time; it is centralised, and truly conceptualised, as the subject of Smith's characteristic linguistic dexterity. In one memorable moment, Sacha, the main character, truly has time on her hands - an egg-timer is superglued to her hand by her brother -- but for Smith, time is not only an object of pun. Instead, time is the central component of a narrative style which relates an ambient pandemic present to the past of the Second World War; drawing links between the Isle of Man internment camps of the 1940 s to immigrant detention centres, both of which exist in the liminal spaces of our national consciousness.

Whilst this juxtaposition of eras may appear simplistic, in the context of Smith's inventive, even avant-garde, exposition of time over the course of the series, it functions as a 
moment of dissolution. In forcing the reader to confront the reality of these camps, at two different moments in history, Smith dissolves the distance between these two moments - she collapses time in upon itself, and this ambience, this proliferation of times, also gestures towards a complex circularity in the political movement of time, both within and outside her series. Society, in Smith, is doomed to repeat itself. The 1940s analepses of the Isle of Man internment camps are conveyed through the memories of a 101-year-old character, Daniel Gluck, who resurfaces in Summer from the pages of Autumn (2016), and just as he re-emerges, so does the political character of crisis; the divisions exposed by Brexit in Autumn are also seen in Summer: leave vs. remain, old vs. young, science vs. politics. However, Smith's mimetic craft combined with the ambient nature of these works, ensures that it is the peculiar sense of the disintegration of boundaries that preoccupies the reader. The distinctions between fiction and reality collapse in the simulacrum of this seasonal quartet, in which past, present, fiction, and reality coexist and coagulate. Time thus appears as both serial and simultaneous. Throughout Smith's quartet, and most clearly present in Summer, is the idea that time is both, it is 'now and ancient, time is before and after....if you try to remove your attachment to time, time will....take the skin off you'. ${ }^{1}$ Sacha comes to understand this quite literally - her hand is stitched back together after its encounter with the egg-timer - creating a 'stitch in time' (77).

Smith stitches time together throughout Summer and, as it is the final instalment in the seasonal series, there are plenty of narrative threads to tie, particularly in terms of realising the connections between characters. These connections have been teased tantalisingly throughout the series, but it is in Summer that the reader is rewarded with an almost Shakespearean character reunion: Daniel Gluck and his neighbour Elizabeth from Autumn and Charlotte and Art from Winter (2017) reconvene. A Barbara Hepworth sculpture, described as a smooth stone with a hole through the middle, is a fitting artistic 'stitch' for this meeting; this object has been carried by Art from the pages of Winter and evinces an ambient entanglement, a sort of material intertextuality, in which Hepworth's sculpture is recognised by the reader from both their own understanding and appreciation of this artist, and from the world of the novel. Further, Hepworth's sculpture is also part of an ongoing socio-cultural conversation in which Smith demands the reader consider artistic representation.

Throughout the series, Smith has ekphrastically championed female cultural production, aligning each instalment of her series to a different female artist: in Autumn ${ }^{1}$ Ali Smith, Summer (UK: Hamish Hamilton, 2020), p.47. Subsequent quotations will be cited parenthetically in the text. 
(2016) the Brit Pop collage artist Pauline Boty dominates, in Winter Hepworth is introduced, Tacita Dean's dreamy images of clouds reoccur throughout Spring (2019), and the director Lorenza Mazetti's aptly titled film, Together (1956), finalises this exploration in Summer. In choosing to centre the cultural world of her novels upon female artistic achievement, Smith reclaims female artistic autonomy and cultural production from the wilderness of a male-dominated artistic canon. Further, by using art as the uniting force for her characters she reminds the reader of the capacity of art to cross divides of time, space, and politics to bring - or stitch - people together.

Smith creates this sense of artistic togetherness herself, within Summer. In one moving passage, Sacha writes to an immigrant, Hero, detained in an immigration centre, of her fears about climate change, her sadness at Hero's continued imprisonment, and the joy of summer swifts. 'If you see a swift in the sky', she writes, 'it's carrying a message from a stranger who wishes you well and is thinking of you' (121). The swift signals the arrival of summer, year after year, as Sacha details and, in the rhythms and renewals of nature and the seasons, change and hope are possible: in winter is summer. Smith plays on this rather tired aphorism by literally, and literarily, including winter in summer by referring explicitly to Shakespeare's The Winter's Tale, a play which is itself, 'all about summer, really' (300). This temporal collapse, between summer and winter, present and Shakespearean past, enacts the ambient entanglement of the seasons, and in so doing, Smith's ambience is ultimately reparative - in writing of the presence of winter in summer through Shakespeare, she reminds the reader of the summery nature of this play, the hopefulness of it. Smith creates the possibility of a hopeful reading here, reminding the reader that 'another world is possible' even 'when you're stuck in the world at its worst', but it is only a possibility - the engagement of the reader is implicitly required here to create change (300).

To create this other world, to enact the restorative potential Smith creates through ambience, the reader must reject apathy, the 'so? ... As in so what?' of Smith's opening pages and of the contemporary political life which she depicts (3). Her interaction with ambience is an integration of the present of the pandemic and 'all manner of virulent things [which] are happening' in cultural life (42). Yet her ambient writing is not time-bound. It is open to the present, creating an immediacy. However, it is not only relevant to the reader at the end of one hot summer - it preserves the present for the future. There is no discordant juxtaposition between past and present, instead Smith's work effectively shows the unifying or entangling powers of art: past, present, and characters are integrated through ekphrasis, natural imagery, and intertextuality. 
Summer, as with the rest of Smith's seasonal quartet, is a call to arms, an activist plea for change and unity. She poses a question and a challenge to the reader through a typically feminist rewrite of David Copperfield (1850) in Summer - demanding readers ask themselves 'whether I shall turn out to be the heroine of my own life' (7). In other words, she asks if we will take action ourselves.

If, with the time on our hands, we can make ourselves new again and come together as nature does, as the novel does, as Smith implores us to - we, too, can find hope, and can change. If not, well, Smith is clear, we will be condemned to recycle our history. 